\title{
Checklist of marine fish from coastal islands of Rio de Janeiro, with remarks on marine conservation-CORRIGENDUM
}

CASSiANO MONTEIRO-NETO, Áthila A. BERTONCINI, LAís DE C.T. CHAVES, RAMON NOGUCHI, JOSÉ P. MENDONÇA-NETO AND CARLOS A. RANGEL

doi:10.1017/S1755267213000973, Published by Cambridge University Press 3 January 2014.

Keywords: reef fish, coastal archipelagos, MoNa Cagarras, Marine Protected Area, south-western Atlantic, corrigendum In the above article the legends for Figures 1, 2 and the images for Figures 4, 5 and 6 were published incorrectly. The corrected versions are below: 
Page 2

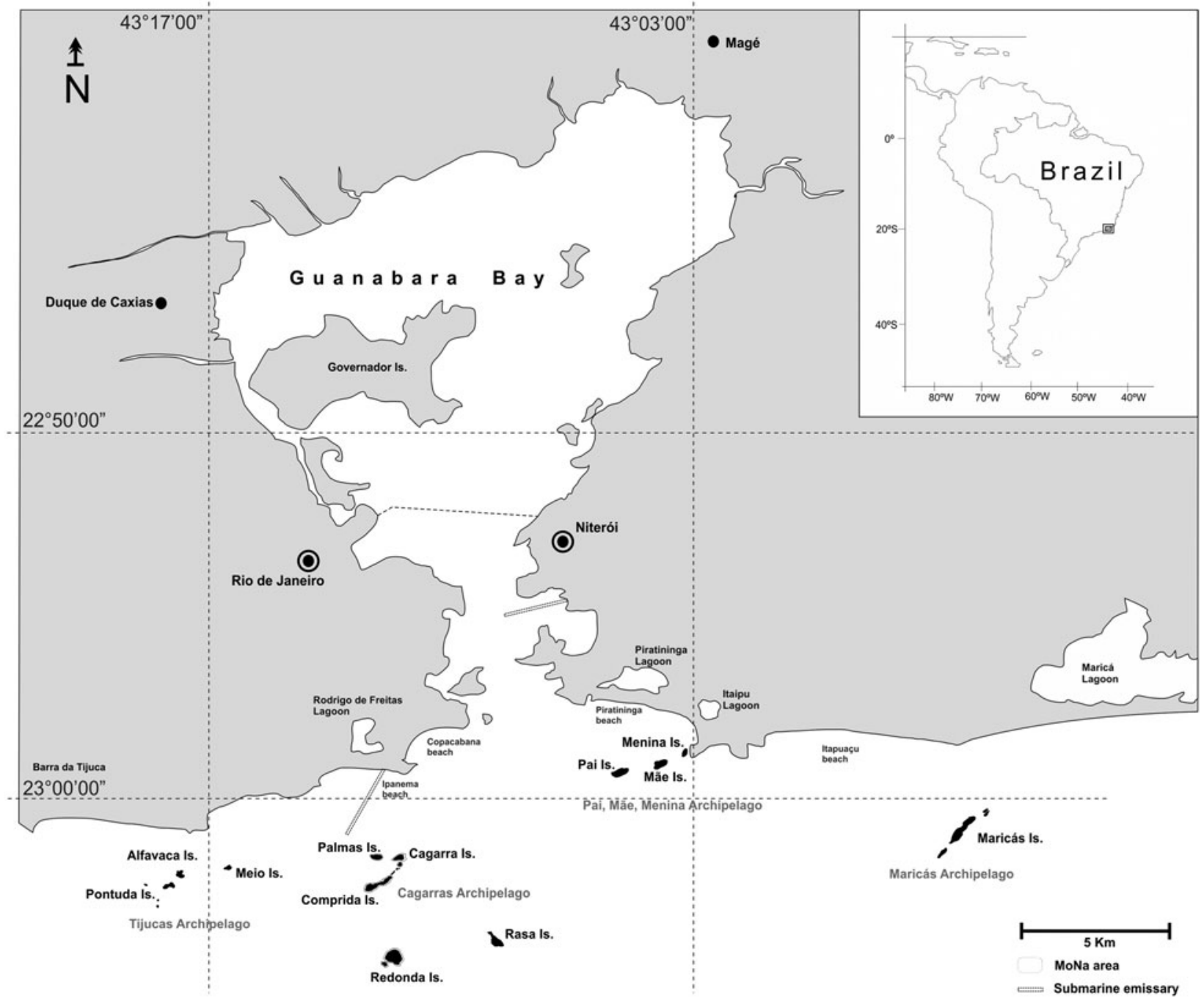

Fig. 1. The coastal islands of Rio de Janeiro (in black): Tijucas; Cagarras; Pai, Mãe, Menina and Maricás Archipelagos, south-eastern coast of Brazil. Dotted area around Palmas, Cagarras, Comprida and Redonda Islands represents the 1om-marine-no-take-zone from the rocky shore of Monumento Natural das Ilhas Cagarras (MoNa Area).

Page 2

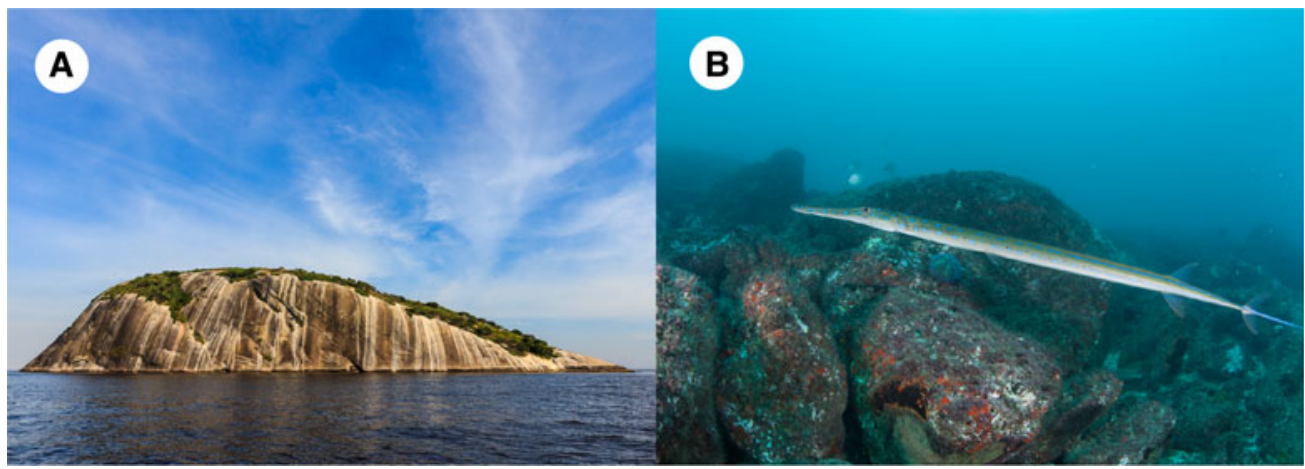

Fig. 2. Northern view of the Cagarras Island (A); Fistularia tabacaria Linnaeus, 1758 over the subtidal area of Redonda Island, formed by granitic boulders of varying sizes and shapes (B) (photograph by A.A. Bertoncini). 
Below are the correct Figures 4, 5 and 6:

Page 8
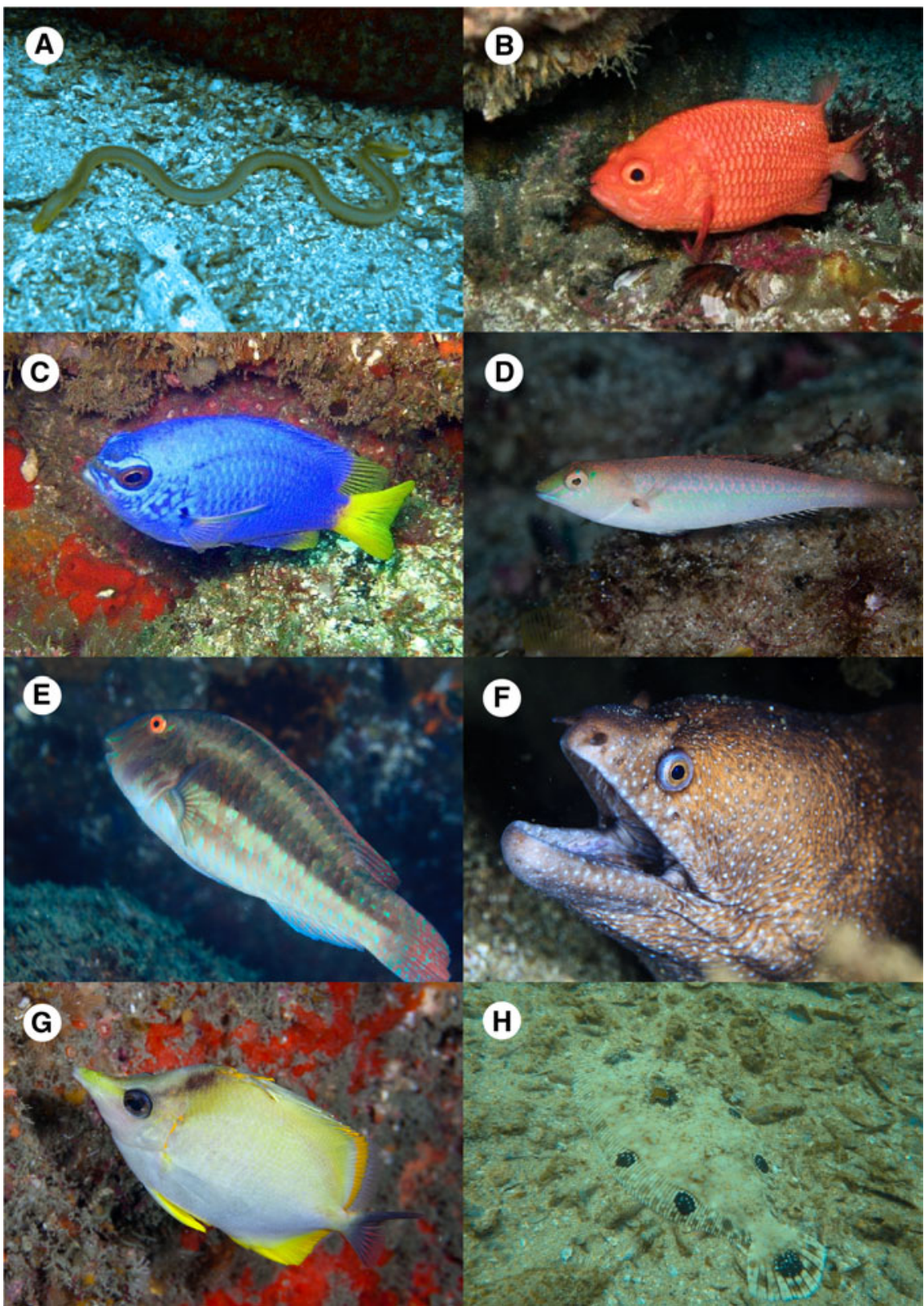

Fig. 4. Selected new records for the area: (A) Ahlia egmontis (Jordan, 1884); (B) Plectrypops retrospinis (Guichenot, 1853); (C) Chromis flavicauda (Günther, 1880); (D) Cryptotomus roseus Cope, 1871; (E) Nicholsina usta (Valenciennes, 1840); (F) Muraena aff. retifera Goode \& Bean, 1882; (G) Prognathodes brasiliensis Burgess, 2001; (H) Cyclopsetta fimbriata (Goode \& Bean, 1885). Photographs: C.A. Rangel (A-C); A.A. Bertoncini (D-G); W. Vieira (H). 
Page 9

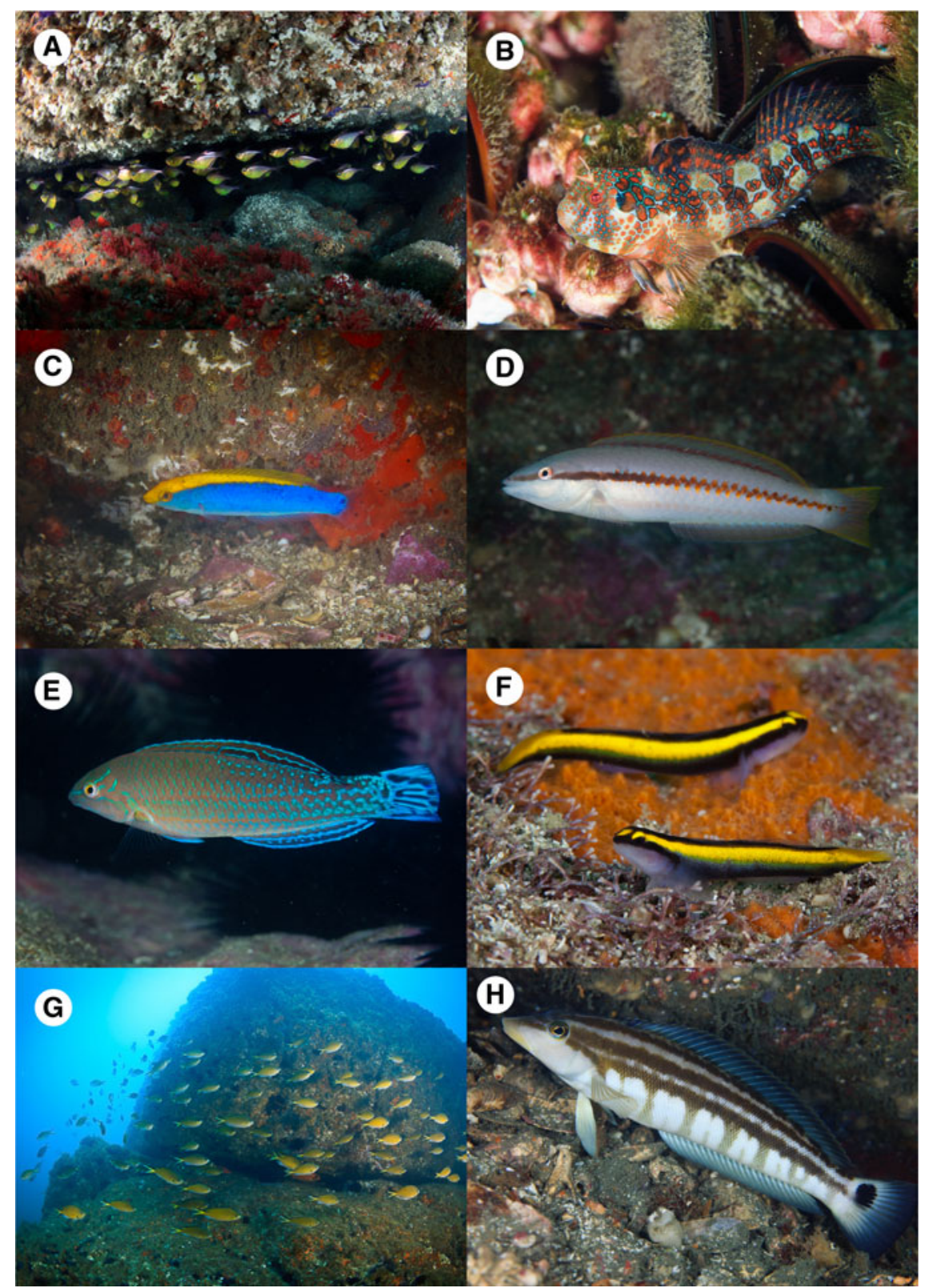

Fig. 5. Selected representatives from the western Atlantic: Pempheris schomburgkii Müller \& Troschel, 1848 (A) and Hypsoblennius invemar Smith-Vaniz \& Acero P., 1980 (B); from the Brazilian Province: Halichoeres dimidiatus (Agassiz, 1831) (C), Halichoeres sazimai Luiz, Ferreira \& Rocha, 2009 (D), Halichoeres brasiliensis (Bloch, 1791) (E) and Elacatinus figaro Sazima, Moura \& Rosa, 1997 (F); the trans-Atlantic: Chromis multilineata (Guichenot, 1853) (G), making use of the boulders and crevices along rocky reef areas in studied sites; and from the southern south-west Atlantic: Pinguipes brasilianus Cuvier, 1829 (H). Photographs: A.A. Bertoncini. 
Page 10

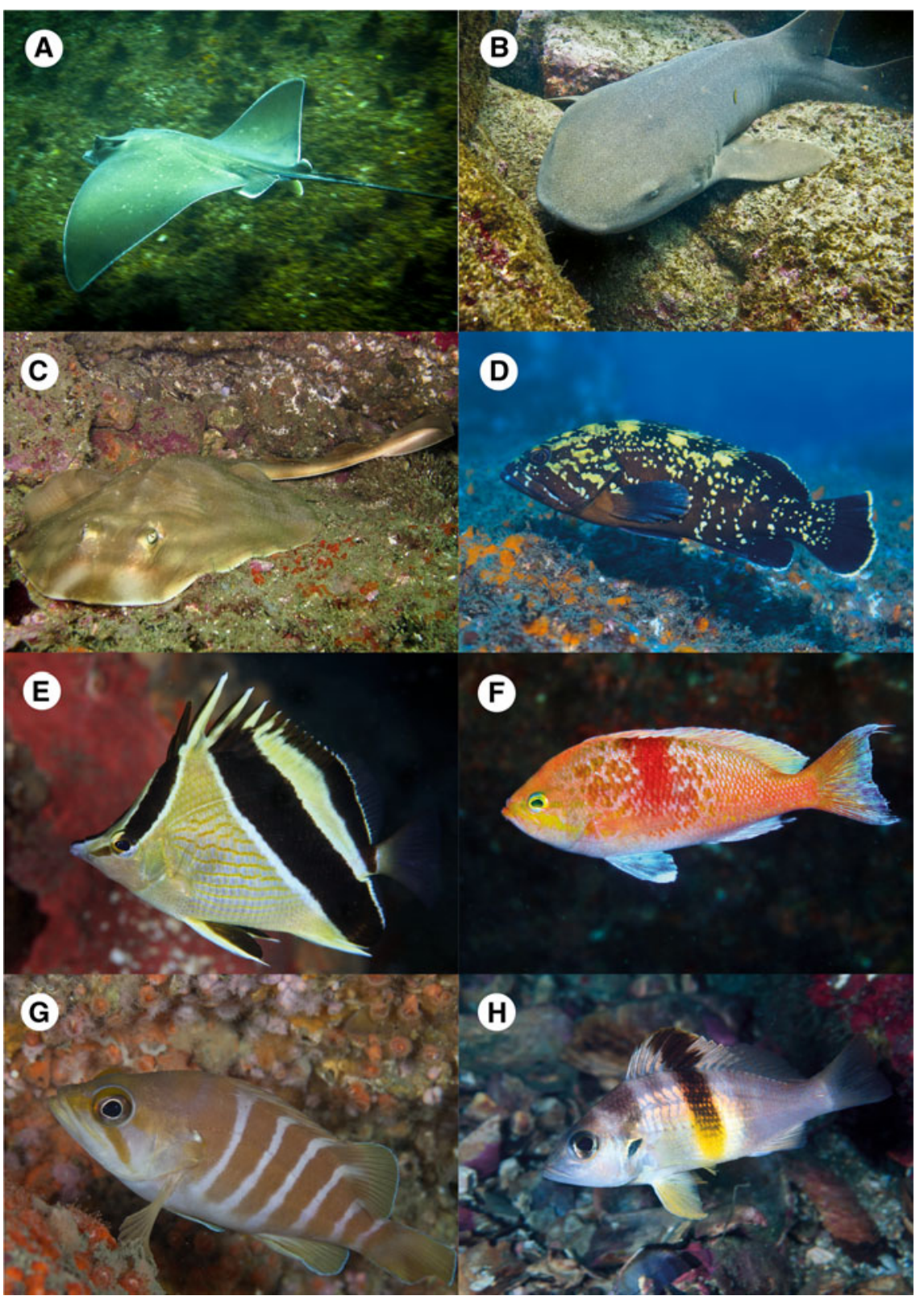

Fig. 6. Elasmobranchs rarely observed on Cagarras rocky reefs: Myliobatis freminvillei Lesueur, 1824 (A), Ginglymostoma cirratum (Bonnaterre, 1788) (B) and Zapteryx brevirostris (Müller \& Henle, 1841) (C); the most common grouper in south and south-east Brazil, Epinephelus marginatus (Lowe, 1834) (D); and the deeper-water group of fish Prognathodes guyanensis (Durand, 1960) (E), Pronotogrammus martinicensis (Guichenot, 1868) (F), Acanthistius brasilianus (Cuvier, 1828) (G) and Serranus atrobranchus (Cuvier, 1829) (H). Photographs: C.A. Rangel (A); J. Iunes (B); F. Moraes (C); Bertoncini (D-H).

\section{REFERENCE}

Monteiro-Neto C., Bertoncini Á.A., Chaves Laís de C.T., Noguchi R., Mendonça-Neto J.P. and Rangel C.A. (2013) Checklist of marine fish from coastal islands of Rio de Janeiro, with remarks on marine conservation. Marine Biodiversity Records. e139. doi:10.1017/S1755267213000973. 